\title{
Esophageal intramural pseudodiverticulosis characterized by barium esophagography: a case report
}

\author{
Owen J O'Connor*1, Adrian Brady¹, Fergus Shanahan², Eamonn Quigley², Michael O'Riordain and Michael M Maher
}

\begin{abstract}
Introduction: Esophageal intramural pseudodiverticulosis is a rare condition characterized by the dilatation of the submucosal glands.
\end{abstract}

Case presentation: We present a case of esophageal intramural pseudodiverticulosis in a 72-year-old Caucasian man who presented with dysphagia and with a background history of alcohol abuse. An upper gastrointestinal endoscopy of our patient showed an esophageal stricture with abnormal mucosal appearances, but no malignant cells were seen at biopsy. Appearances on a barium esophagram were pathognomonic for esophageal intramural pseudodiverticulosis.

Conclusion: We demonstrate the enduring usefulness of barium esophagography in the characterization of abnormal mucosal appearances at endoscopy.

\section{Introduction}

Esophageal intramural pseudodiverticulosis is a rare condition characterized by the dilatation of submucosal glands. Based on approximately 250 cases reported to date, this condition is slightly more common in men than in women [1,2]. Intramural pseudodiverticulosis is most commonly associated with gastrooesophageal reflux and esophagitis and less commonly with alcoholism, diabetes mellitus, Crohn's disease, tuberculosis, Mallory-Weiss syndrome and achalasia $[3,4]$. The average age at presentation is 54 years and patients typically present with dysphagia, which is frequently associated with stricture formation, as in case we describe here [3,4]. Symptoms usually respond well to anti-inflammatory medication and balloon dilatation of strictures.

\section{Case presentation}

A 72-year-old Caucasian man (height: $170 \mathrm{~cm}$, weight: 85 $\mathrm{kg}$ ) presented with a 4-year history of mild dysphagia for solid foods. His medical history was notable for alcohol abuse and associated alcoholic hepatitis. An upper gastrointestinal endoscopy was initially performed on our

\footnotetext{
* Correspondence: owen.oconnor7@gmail.com

1 Department of Radiology, Mercy University Hospital, Cork, Ireland

Full list of author information is available at the end of the article
}

patient. At endoscopy, a stricture of the mid-esophagus with numerous tiny erythematous macules on the mucosal surface was seen (Figure 1). There was clinical uncertainty about the cause of the stricture and the mucosal appearances. A barium esophagogram was performed (Figures 2A and 2B). Barium esophagogram demonstrated a smooth stricture of the mid-esophagus with numerous small ( $2 \mathrm{~mm}$ to $4 \mathrm{~mm}$ ), flask-shaped outpouchings of the esophageal wall, an appearance which is pathognomonic for esophageal intramural pseudodiverticulosis [5].

\section{Discussion}

Biphasic esophagography is generally recommended for the evaluation of an esophageal stricture. While a single contrast barium esophagogram provides maximal esophageal dilatation and is useful for the depiction of a stricture, a double contrast examination allows accurate imaging of the esophageal mucosa and wall. Barium esophagram is valuable for establishing this particular diagnosis as reports in the literature have suggested that the diverticular orifices are detected at endoscopy in only $20 \%$ of patients [2]. 


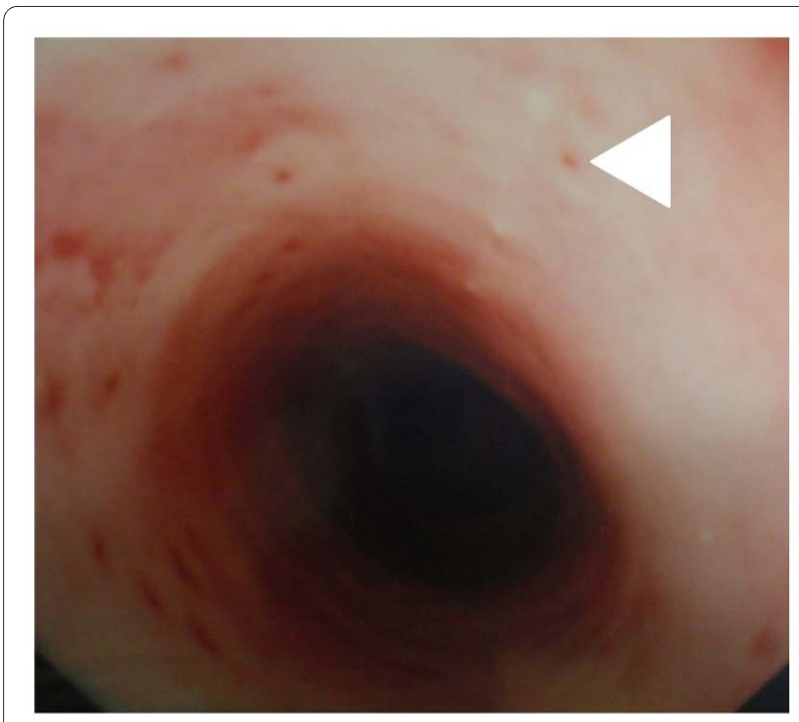

Figure 1 Endoscopic image of the esophagus. The pseudodiverticular orifices appear as multiple erythematous macules on the surface of the esophagus.

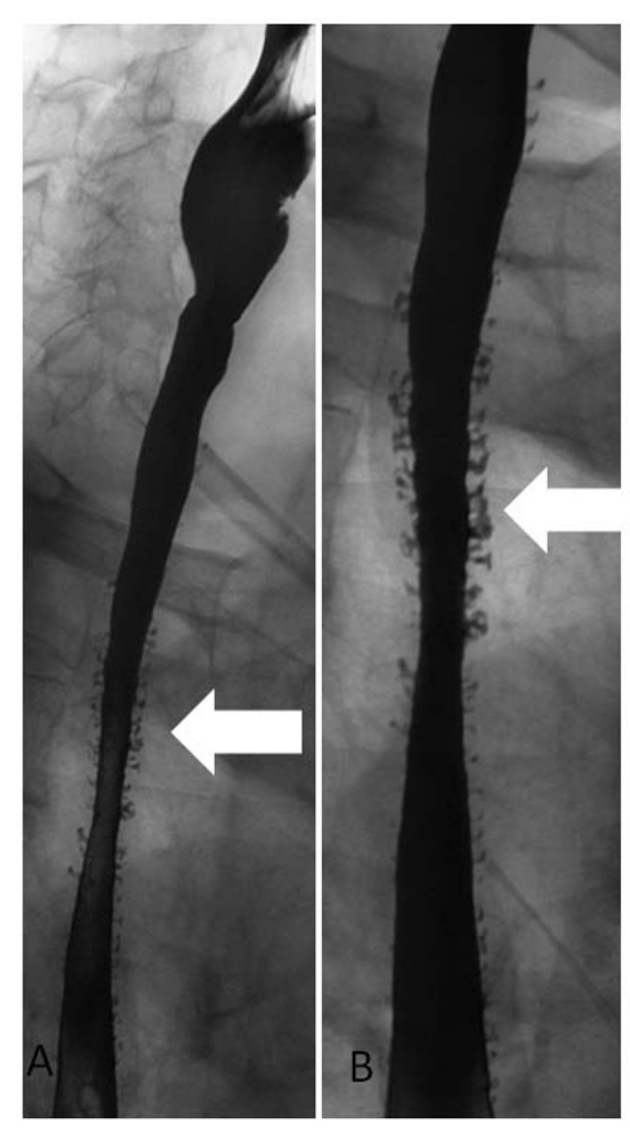

Figure 2 Barium oesophagram. (A) There are numerous bariumfilled diverticula of the mid- and lower esphagus. (B) There is lack of distension of the mid-esophagus, thus indicating the presence of a stricture.

\section{Conclusion}

This case demonstrates the enduring usefulness of barium esophagography in the characterization of peculiar mucosal appearances at endoscopy.

\section{Consent}

Written informed consent was obtained from our patient for publication of this case report and any accompanying images. A copy of the written consent is available for review by the Editor-in-Chief of this journal.

\section{Competing interests}

The authors declare that they have no competing interests.

\section{Authors' contributions}

OJOC prepared the manuscript. MOR performed upper gastrointestinal endoscopy. $A B$ and MM performed barium esophagography. FS and EQ medically managed our patient. All authors read and approved the final manuscript.

\section{Author Details}

'Department of Radiology, Mercy University Hospital, Cork, Ireland, 2Department of Medicine, University College Cork, Cork, Ireland and ${ }^{3}$ Department of Surgery, Mercy University Hospital, Cork, Ireland

Received: 3 December 2009 Accepted: 21 May 2010 Published: 21 May 2010

\section{References}

1. VanLaer W, Urbain D, Reynaert H: Esophageal intramural pseudodiverticulosis. Clin Gastroenterol Hepatol 2007, 5(12):A22.

2. Herter B, Dittler HJ, Wuttge-Hannig A, Siewert JR: Intramural pseudodiverticulosis of the esophagus: a case series. Endoscopy 1997 29:109-113

3. Flora KD, Gordon MD, Lieberman D, Schmidt W: Esophageal intramural pseudodiverticulosis. Dig Dis 1997, 15:113-119.

4. Bhattacharya S, Mahmud S, McGlinchey I, Schmidt W: Intramural pseudodiverticulosis of esophagus. Surg Endosc 2002, 16:714-715

5. Luedtke P, Levine MS, Rubesin SE, Weinstein DS, Laufer I: Radiologic diagnosis of benign esophageal strictures: a pattern approach. Radiographics 2003, 23(4):897-909.

doi: 10.1186/1752-1947-4-145

Cite this article as: O'Connor et al., Esophageal intramural pseudodiverticulosis characterized by barium esophagography: a case report Journal of Medical Case Reports 2010, 4:145

\section{Submit your next manuscript to BioMed Centra and take full advantage of:}

- Convenient online submission

- Thorough peer review

- No space constraints or color figure charges

- Immediate publication on acceptance

- Inclusion in PubMed, CAS, Scopus and Google Scholar

- Research which is freely available for redistribution 